\title{
Mast cells are major contributors to the pathophysiology of Graves' Ophthalmopathy (GO)
}

\author{
L Van Steensel $1^{1 *}$, D Paridaens ${ }^{3}$, P M van Hagen ${ }^{1}$, RWAM Kuijpers ${ }^{2}$, W A Van den Bosch ${ }^{3}$, H A Drexhage ${ }^{1}$, \\ H Hooijkaas ${ }^{1}$, W A Dik
}

From 5th European Workshop on Immune-Mediated Inflammatory Diseases

Sitges-Barcelona, Spain. 1-3 December 2010

\section{Introduction}

Mast cell numbers are elevated in GO orbital tissue and are mainly located adjacent to orbital fibroblasts. Mast cells are potent producers of a variety of factors, such as histamine and tryptase. Mast cell stabilizing agents resulted in clinical improvements in GO patients. These data suggest an important role for mast cells in GO and warrants further studies into their contributing role.

\section{Aim}

These studies were performed to confirm the increased presence of mast cells in orbital tissue from GO patients. Furthermore, the effects of the mast cellderived mediators histamine and tryptase on several key processes in the GO pathophysiology (orbital fibroblast proliferation, hyaluronan and cytokine production) were examined.

\section{Methods}

To identify mast cells, orbital tissues were stained with toluidine blue. Furthermore, orbital fibroblast cultures were stimulated with histamine or tryptase and IL- 6 and hyaluronan production and orbital fibroblast proliferation were determined. Involvement of proteinase-activating receptor (PAR)-2 and histamine receptor 1 (HR1) and histamine receptor 2 (HR2) was investigated using specific inhibitors (ENMD-1068, Cetirizine and Cimetidine, respectively).

\section{Results}

Increased mast cell numbers located predominantly adjacent to fibroblast-like cells were observed in GO orbital tissue. Histamine induced IL-6 and hyaluronan production through HR1, while tryptase induced IL-6 and hyaluronan production via PAR-2. Both factors increased orbital fibroblast proliferation modestly.

\section{Conclusion}

Mast cells are important in the pathophysiology of GO, as their numbers are increased in GO orbital tissue and their products histamine and tryptase stimulate cytokine and hyaluronan production as well as orbital fibroblast proliferation. Therefore, mast cells contribute to the orbital inflammation and tissue expansion typical for GO. These data give a rationale for the promising treatment results obtained with mast cell stabilizing agents in the treatment of GO patients and supports further studies therein.

\section{Author details}

'Department of Immunology, Erasmus MC, University Medical Center, Rotterdam, The Netherlands. ${ }^{2}$ Department of Ophthalmology, Erasmus MC, University Medical Center, Rotterdam, The Netherlands. ${ }^{3}$ Rotterdam Eye Hospital, Rotterdam, The Netherlands.

Published: 25 November 2010

doi:10.1186/1479-5876-8-S1-P22

Cite this article as: Van Steensel et al:: Mast cells are major contributors to the pathophysiology of Graves' Ophthalmopathy (GO). Journal of Translational Medicine 2010 8(Suppl 1):P22. 